\title{
Erratum to: Descriptive study of the courses offered in degree programs in Biomedical Engineering in Mexico
}

\author{
A. Pliego-Carrillo, E. Del Hierro-Gutierrez
}

\section{Erratum to:}

Chapter "Descriptive study of the courses offered in degree programs in Biomedical Engineering in Mexico" in: I. Torres et al. (eds.), VII Latin American Congress on Biomedical Engineering CLAIB 2016,

Bucaramanga, Santander, Colombia, October 26th -28th, 2016, IFMBE Proceedings 60, https://doi.org/10.1007/978-981-10-4086-3_177

The original version of the book was inadvertently published with incorrect title for Chapter 177 in XML and book PDF (TOC), which has to be now corrected. The erratum book has been updated with the change.

The updated online version of this chapter can be found at https://doi.org/10.1007/978-981-10-4086-3_177

(C) Springer Nature Singapore Pte Ltd. 2018 